\title{
SEMANTIC CATEGORIES IN IDEOGRAPHIC DICTIONARIES
}

\author{
Sergey N. Vinogradov \\ Lobachevsky State University of Nizhny Novgorod, Nizhny Novgorod, Russia
}

\begin{abstract}
The paper considers semantic categories presented in the ideographic discourse. Research material includes the information retrieval thesauruses reflecting scientific information activities and functional and ideographic dictionaries representing the discourse of training in writing school compositions and the epistolary discourse (letters of Russian writers). The author regards semantic categories as sign units (sign formations) whose content plane is general concepts, and denotation is various language (sign) means forming this general concepts. The article shows that semantic categories, as the result of categorization, reflect properties of the discourse - the functional and communicative field in which it appears, characteristics of the speech subject, character of the relation of the author of the text to its topic and to the addressee, interaction with the language code. The paper discusses the technique of semantic category choice, the formation of their list, their participation in creating the classification schemes of concepts, the opportunities of using ideographic dictionaries to solve linguistic and pedagogical tasks. The article provides the conclusions on the existence and nature of system communications of ideographic semantic categories with such cognitive aspects of the language as a problem situation in word using and understanding, classification of lexical units and concepts, psychology of thinking in language forms, specifics of extralinguistic factors in scientific and language activity in different private discourses.

Key words: semantic category, sign unit, ideographic dictionary, classification scheme, lexical choice, discourse, lexicography.

Citation. Vinogradov S.N. Semantic Categories in Ideographic Dictionaries. Vestnik Volgogradskogo gosudarstvennogo universiteta. Seriya 2, Yazykoznanie [Science Journal of Volgograd State University. Linguistics], 2019, vol. 18, no. 1, pp. 23-32. (in Russian). DOI: https://doi.org/10.15688/jvolsu2.2019.1.2
\end{abstract}

УДК 81'374:81’42

Дата поступления статьи: 21.12.2018

ББК $81.054-421$

Дата принятия статьи: 18.02.2019

\section{СМЫСЛОВЫЕ КАТЕГОРИИ В СЛОВАРЯХ ИДЕОГРАФИЧЕСКОГО ТИПА}

\section{Сергей Николаевич Виноградов}

Нижегородский государственный университет им. Н.И. Лобачевского, г. Нижний Новгород, Россия

\begin{abstract}
Аннотация. Смысловые категории (СК), эксплицированные в идеографическом дискурсе, рассматриваются на материале информационно-поисковых тезаурусов, отражающих научно-информационную деятельность, и функционально-идеографических словарей, в которых представлены дискурс обучения написанию школьных сочинений и эпистолярный дискурс (письма русских писателей). В статье предложено опреح деление СК как знаковой единицы (знакового образования), содержанием которого являются общие поня궁 тия, а денотатами - разнообразные языковые (знаковые) средства, формирующие общее понятие. Показано, что, будучи результатом категоризации, СК отражает свойства дискурса - функционально-коммуникативную сферу, в которой она возникает, характеристики речевого субъекта, характер отношения автора текста к \% его теме и адресату, взаимодействие с языковым кодом. Рассмотрены методики выбора СК и формирования : вания идеографических словарей при решении лингвистических и педагогических задач. Сделаны выводы о характере системных связей идеографических СК с такими когнитивными аспектами языка, как проблемная () ситуация в словоупотреблении и понимании, классификация лексических единиц и понятий, психология
\end{abstract}


мышления в языковых формах, специфика экстралингвистических факторов в научно-языковой деятельности в разных частных дискурсах.

Ключевые слова: смысловая категория, знаковая единица, идеографический словарь, классификационная схема, лексический выбор, дискурс, лексикография.

Цитирование. Виноградов С. Н. Смысловые категории в словарях идеографического типа // Вестник Волгоградского государственного университета. Серия 2, Языкознание. - 2019. - T. 18, № 1. - С. 23-32. - DOI: https://doi.org/10.15688/jvolsu2.2019.1.2

\section{Введение}

Актуальность изучения смысловых категорий в лексикографии связана, с одной стороны, с интересом лингвистов к когнитивным процессам категоризации в языке, а с другой с необходимостью создания словарей идеографического типа, в структуре которых отражены процессы и результаты категоризации. Цель статьи - на основе семиотического понимания категории выявить смысловые категории (далее - СК), которые находят выражение в текстах лексикографического характера, имеющих идеографическую составляющую, - в информационно-поисковых тезаурусах и функционально-идеографических описаниях лексики разных дискурсов.

\section{Исходные понятия и определения}

В русском языке слово категория многозначно. Согласно данным толковых словарей оно, во-первых, функционирует как термин в значении «общее понятие, отражающее наиболее существенные связи и отношения реальной действительности и познания», а вовторых, выражает неспециализированное значение «группа лиц, предметов, явлений, объединенных общностью каких-нибудь признаков» (см., например: Ожегов, Шведова, с. 275). В приведенных толкованиях представлено разноепонимание категории - как идеальной сущности и как группы предметов, «вещей». Эти же значения зафиксированы в философских словарях. Категории определяются как философские (Современный философский словарь, c. 312; Философский энциклопедический словарь, с. 204), фундаментальные понятия (Новая философская энциклопедия, с. 229), формы осознания в понятиях способов отношения человека к миру (Философский словарь, с. 237). Вместе с тем отмечается, что в разговорном языке категория - то же самое, что вид, сорт, класс, ранг, «определенная категория служащих» (Философский энциклопедический словарь, с. 204). В психологическом словаре подчеркивается неоднозначность этого термина: «Одни авторы используют его, как будто он относится к реальным классам... Другие используют этот термин, как будто он относится к мысленным представлениям об этом классе в сознании человека... Некоторые предпочитают обращаться с этим термином прагматично и позволяют образцам поведения или употребления диктовать границы классов...» (Большой толковый психологический словарь, с. 344).

Таким образом, категория понимается и как мыслительная сущность (понятие), и как реальная совокупность объектов («вещей»).

Приведенные толкования этого термина соотносятся с составными частями знаковой ситуации - предметом и мысленным представлением (общим понятием). По-видимому, создание категорий - разновидность знаковой деятельности, в которой сами категории включены в знаковую ситуацию. Это должно учитываться при трактовке термина «категория». Например, в лингвистике существует определение морфологической категории как единства противопоставленных морфологических значений и средств их выражения. Такая трактовка соответствует дефиниции знака, приведенной Ф. де Соссюром: знак - «соединение понятия и акустического образа» [Соссюр, 1977, с. 100].

В лингвистике, как и в философии, категорию нередко характеризуют как феномен только плана содержания (например, как множества взаимоисключающих обязательных значений [Плунгян, 2011, с. 10]), но при этом имеют в виду и то, чем это содержание выражено, и название категории. Данное понятие конкретизируется посредством языковедческих терминов «грамматическая категория», «смысловая категория», «семантическая ка- 
тегория», «понятийная категория». Процессы категоризации и их результаты не могут быть осмыслены без денотата, в котором представлена категория, и названия этой категории, закрепляющего ее существование в мысли. Например, СК «количество» в языке охватывает разноуровневые языковые средства лексические единицы (один, пять, несколько, много, многие и т. д.), словообразовательные (например, суффиксы, обозначающие множественность или единичность: листва, горошина и т. д.) и морфологические средства (формы числа существительного) и др., а семантика этой категории - понятие 'количество'. Обобщающее слово количество - вербализация данной категории, экспонент обобщенной знаковой единицы.

Под СК будем понимать результат когнитивного процесса категоризации - знаковую единицу (знаковое образование), планом содержания которой (которого) является общее понятие, а денотатом - разнообразные языковые (или шире - знаковые) средства, формирующие это общее понятие [Виноградов, 2016, c. 7].

\section{Методы}

В исследовании был использован общенаучный описательный метод. Объектом описания явились категориальные значения, возникающие в языке и частных дискурсах. Из лингвистических методов исследования использовался когнитивный метод, поскольку категоризация, сущность которой анализируется в статье, является одним из основных когнитивных процессов.

\section{Идеографический словарь как сфера формирования смысловых категорий}

Поскольку процесс категоризации универсален в той же степени, что и когнитивный аспект языка, СК обнаруживаются в различных сферах языкового функционирования и дискурсах. Например, СК являются названия функционально-семантических полей, отражающие разноуровневые языковые средства [Бондарко, 1990], терминологические единицы, образующие язык науки и охватывающие множества частных описаний фактов (ср. клас- сифицирующую функцию терминов в [Головин, Кобрин, 1987, с. 13; Куликова, Салмина, 2002 , с. 96; Скороходько, 1970, с. 160]), названия классов в библиотечных классификациях, дескрипторы информационно-поисковых языков как названия классов условной эквивалентности [Черный, 1975, с. 63].

В когнитивной лингвистике, вслед за Э. Рош и Дж. Лакоффом, утверждается динамический характер категорий. Так, Дж. Лакофф противопоставил традиционный логический взгляд и категоризацию под влиянием психофизиологических особенностей человека [Лакофф, 1988], в результате которой категории оказываются нечеткими классами с размытыми границами. Идея нечетких классов в языкознании не нова. Она берет начало в лингвистических теориях поля (см., например: [Щур, 1974]) и конкретизируется в работах, где функционально-семантические поля и другие языковые классы представлены как структуры, имеющие центр и периферию [Адмони, 1964; Бондарко, 1984; Гухман, 1971; Плунгян, 2003].

Динамизм формирования категорий, нечеткость представленных в них классов отражают динамизм когнитивной деятельности. Процесс категоризации осуществляется в условиях проблемной ситуации. В качестве таковых будем рассматривать ситуацию, имеющую более чем одну возможную альтернативу решения. Проблемными являются, например, ситуация выбора слова, когда приходится иметь дело с набором возможных вариантов названия, или понимания, когда носитель языка сталкивается с неоднозначностью толкования слова или определения понятия. Повидимому, проблемная ситуация всегда возникает при функционировании языковых единиц. Используя то или иное слово, носитель языка решает проблему выбора наилучшей формулировки [Виноградов, 2007, с. 266] (ср. выбор синонима при построении речи). В таком случае слово оказывается одной из альтернатив решения проблемы. Интерпретируя его или другую языковую единицу, носитель языка также решает проблему, поскольку интерпретация, как правило, не единична. В этом случае слово соотносится с множеством возможных интерпретаций и является вербальным выражением наличия проблемы выбора интерпретации. 
Очевидно, что проблемная ситуация имеет место и в лексикографической работе. Словари можно сравнить с ответом к некоторой лингвистической задаче [Караулов, 1981, c. 42], и лексикограф тоже имеет дело с выбором. При составлении идеографических словарей проблемами являются выбор тематических областей, их наименований и лексики, наполняющей эти предметные области. Готовый идеографический словарь позволяет пользователю решать проблему выбора слов для выражения того или иного смысла (смыслового содержания, понятия).

\section{Смысловые категории}

\section{В информационно-поисковом тезаурусе}

При составлении информационно-поисковых тезаурусов необходима разработка классификационной схемы отраженных в нем понятий. Эта схема - один из источников лексических единиц для словаря и одновременно средство категоризации лексики. Названия ее классов являются СК в определенном выше смысле. Примерами таких названий могут служить следующие: МАТЕРИАЛЫ (лексика, обозначающая различные вещества, сырье, готовую продукцию, химические элементы и соединения), ОБОРУДОВАНИЕ (инструменты, приборы, машины, их части и детали и т. д.), ПРОЦЕССЫ (интеллектуальные, физико-химические, технологические и др.), КАЧЕСТВА (свойства, параметры, характеристики), ПРОЧЕЕ (теоретические понятия, географические названия, учреждения, персонал и т. д.) [Виноградов и др., 1981].

Такой или приблизительный набор СК может применяться в тезаурусах различных промышленных областей. Следует заметить, что выбор категорий и принадлежность к ним лексики предполагает прагматические решения, нарушающие строгость логических классификаций. Например, в тезаурусах по производству строительных материалов (разделы «Стекло и стеклоизделия» (ИПТ, 1980), «Цементная промышленность» (ИПТ, 1981), «Керамическая промышленность» (ТИП)) в категорию МАТЕРИАЛЫ попадают не только названия собственно материалов, но и изделия, изготовленные из них: стеклоизделие, блок стеновой, изделие керамическое и т. д.
Информационно-поисковый тезаурус представляет собой некоторую систему классификации, а его создание определяется правилами и методиками классифицирования. К области методики индексирования относятся иерархический и фасетный принципы составления классификационной схемы тезауруса.

В основе иерархической классификации лежит логическая операция деления понятия. В специальной литературе перечисляются формально-логические правила данной операции: деление понятий (классов) должно производиться только по одному основанию и быть соразмерным и непрерывным, а получаемые в результате подклассы - исключать друг друга [Черный, 1975, с. 37]. Однако эти строгие требования к классификации оказываются нежизнеспособными при построении тезауру$\mathrm{ca}$, так как противоречат психологической реальности, в которую «погружен» процесс создания словарей данного типа. Категоризация и классификация как деятельность носителей языка и составителей словарей носят «размытый», нечеткий характер. Поэтому на принцип иерархического строения, хотя сам он в указанной деятельности необходим, накладываются ограничения: при выделении лексических единиц, выражающих частные понятия, неизбежны различные основания этого выделения; подклассы лексики могут пересекаться (это проявляется в том, что одна и та же лексическая единица может попасть в разные категории и, соответственно, иметь разные вышестоящие лексические единицы); при выделении лексических единиц могут быть лакуны в содержании, которые не имеют названий (обозначений).

В основе фасетной классификации лежит фасетный анализ, идея которого принадлежит индийскому библиотековеду Ш.Р. Ранганатану [Черный, 1975, с. 52]. Этот анализ начинается с составления перечня основных категорий объектов, применяемых в описываемой предметной области, - фасетов. Затем из корпуса текстов выписываются все важные лексические единицы и группируются по фасетам, то есть объединяются в соответствующие классы. Множество лексических единиц, обозначающих материалы, объединяются в фасет «Материалы», свойства, параметры, характеристики - в фасет «Качество» и т. д. 
Фасетная классификация лексики предполагает использование иерархического принципа, так как лексические единицы внутри фасета принадлежат к разным уровням иерархии и позволяют устанавливать в словаре иерархические отношения внутри лексического состава. Перечисленные выше СК МАТЕРИАЛЫ, ОБОРУДОВАНИЕ и т. Д. явЛяюТся по существу названиями фасетов.

Фасеты - не результат деления единого понятия, а форма отражения различных аспектов рассмотрения предметной области. Это делает их гибким средством описания, например, в области библиографии, когда описываемый документ не принадлежит к некоторой заранее заданной рубрике, а характеризуется лексикой из разных фасетов. По-видимому, фасетный принцип отражает психологическую реальность классификации, а именно - ее творческий характер, когда классифицируемый предмет не относят к готовому классу, а синтезируют классификационные признаки этого предмета, которые в дальнейшем позволяют объединять сходные классифицируемые предметы в один класс.

Чтобы задать список фасетов, необходимо выделить аспекты рассмотрения предметной области, которые зависят от дискурса использования лексических единиц. Дискурс, в котором используется информационнопоисковый тезаурус, - информационная деятельность. При составлении такого типа тезаурусов влияние дискурса определяется в первую очередь тематическим охватом, который отражается в отборе лексического состава словаря. В информационно-поисковых тезаурусах разных отраслей этот охват различен. Тем не менее есть общие когнитивные закономерности языка, которые отражены в процессах составления тезауруса, - необходимость категоризации лексики и прагматический характер этой категоризации. В.Е. Чернявская выделяет в коммуникативной ситуации ряд экстралингвистических факторов: 1) функционально-коммуникативную сферу, в которой создается и воспринимается текст: обиходно-бытовая, официально-деловая, научная, религиозная, литературно-художественная и прочие сферы человеческой деятельности и общения; 2) индивидуально-социальные характеристики речевого субъекта, порождаю- щего текст, а именно - возрастная, профессиональная, социальная, гендерная и другие характеристики; 3) характер отношения субъекта речи к ее адресату: непринужденный, официальный, коллегиальный и др.; 4) характер отношения автора текста к его теме / содержанию: нейтральный, эмоционально-оценочный, субъективно отмеченный, подчеркнуто объективный, профессионально-специальный и др.; 5) взаимодействие с языковым кодом: стилистически осознанное, намеренно разговорное или метафорическое употребление языка и др. [Чернявская, 2006, с. 12-13]. Думается, что по крайней мере часть этих факторов играет важную роль в прагматике составления и использования информационно-поисковых тезаурусов - в принятии тех или иных «рабочих решений» при их составлении.

\section{СК в функционально-идеографическом словаре}

В словарях идеографического типа могут найти отражение частные дискурсы, столь же разнообразные, как и человеческая деятельность в целом. В качестве примера реализации такой возможности рассмотрим функционально-идеографический словарь, составленный в процессе учебной деятельности, содержание которой - обучение школьников написанию сочинений на литературную тему. Под функционально-идеографическим понимается «словарь, содержащий различные языковые средства выражения одного и того же смысла и особенности употребления этих языковых средств в речи» [Виноградов, 1997, с. 78]. В школьном сочинении выделяется специфический для этого вида текстов набор элементов содержания: характеристика, событие, сопоставление, источник информации, цель, причина, точка зрения, уверенность, предположение, акцент, вывод [Козлинская, 2009, c. 256] (по принятой нами терминологии, это перечисление СК). В процессе составления функционально-идеографического словаря осуществляется отнесение лексики к определенной СК (или, наоборот, выражение определенной СК с помощью определенных лексических и других языковых единиц).

В качестве источников языковых единиц, относящихся к различным СК, О.А. Козлинс- 
кая использует текстовые фрагменты «образцовых» сочинений, представленных в сборниках для подготовки абитуриентов к вступительным экзаменам. Здесь обнаруживается параллель с методикой подготовки информационно-поискового тезауруса на базе лексических единиц, отобранных из специальной литературы. Например, О.А. Козлинская, описывая функционально-семантическое поле «Сопоставление», выделяет в текстовых фрагментах обороты со словами служебных частей речи «более... чем...», «менее... чем...», «так (же)... как (и)...», «в отличие от...», вводные слова, выражающие противопосталение одной мысли другой, противительные союзы в простом и сложносочиненном предложении, бессоюзные сложные предложения и т. д. [Козлинская, 2011, с. 364]. Другие функциональносемантические поля также представлены языковыми единицами и содержащими их текстовыми фрагментами.

В качестве методического средства для выбора СК возможно использование текста, который описывает предметную область, охватываемую функционально-идеографическим словарем. Например, описание дискурса обучения школьному сочинению может содержать названия самих блоков, их места и роли в процессе обучения, характеристику наполнения.

Примером использования СК в функционально-идеографическом словаре служит словарь по письмам русских писателей (общая идея такого словаря выражена в [Виноградов, 1997] и реализована нами в черновом варианте). Материалом для составления такого словаря послужили более 2000 текстовых фрагментов из опубликованных писем А.А. Ахматовой, К.Д. Бальмонта, А.А. Блока, М.А. Булгакова, М. Горького, Н.С. Гумилева, О.Э. Мандельштама, К.Г. Паустовского, А.П. Платонова, И.С. Соколова-Микитова, М.И. Цветаевой, А.П. Чехова.

Словарь построен по функционально-идеографическому принципу. Тематические области, которые учитываются при упорядочении материала, - беспокойство, благодарность, возражение, жалоба и сожаление, извинение, напоминание, обещание, одобрение, «письмо Ваше получил» (ситуация, описываемая не отдельной лексической единицей, а целым высказыванием), пожелание, порицание, предло- жение и совет, предположение, приветствие, признание (действие по глаголу признаться), просьба, радость, согласие, сочувствие, удивление, утешение. Лексические единицы беспокойство, благодарность, возражение и т. д. являются названиями СК. Под эти категории подводятся смысловые единицы, которые могут быть эксплицированы словами, словосочетаниями, предложениями, текстовыми фрагментами. Указанные тематические области (и содержание соответствующих СК) описываются посредством определений из толковых словарей и на основе содержательных комментариев. Например:

БЕСПОКОЙСТВО. Значение этого слова, отраженное в словарях, - тревожное состояние, волнение. Принимается во внимание только беспокойство, которое испытывает отправитель письма. Диапазон этого состояния, представленный в письмах, от небольшого дискомфорта, легкой неловкости, стеснения, связанного с незначительными причинами (угнетенным состоянием, неудачно сказанным словом, чрезмерно длинным письмом, боязнью злоупотребить вниманием адресата) до сильнейшей тревоги и даже страха. Чаще всего авторы писем беспокоятся о здоровье знакомых, друзей и близких, об условиях их жизни (жилье, денежные средства и др.). Одна из главных причин беспокойства - отсутствие писем от адресата или третьих лиц.

Смысловые единицы упорядочены по тематическим областям. В каждой из них выделяются 5 смысловых блоков: 1) СК, 2) лексические единицы (слова в начальной форме, в отдельных случаях фразеологизмы и свободные словосочетания), передающие содержание данной тематической области и расположенные в алфавитном порядке, 3) список словосочетаний, предложений, речевых оборотов, этикетных формул, передающих данную тематику в виде связного сообщения, 4) текстовые фрагменты, содержащие лексику из 1-го и 2-го блоков, 5) текстовые фрагменты, передающие тематическое содержание не языковыми единицами из 1-го и 2-го блоков, а другими средствами (например, подтекстом).

Приведем фрагмент словарного описания одной из тематических областей. Цифры обозначают номера смысловых блоков, отточия вакантные места, которые в высказываниях могут быть заменены различными (произвольными) элементами. Скобки в блоке 2 выделя- 
ют необязательные (факультативные) элементы. Запятые в блоке 3 обычно отделяют вариативные части словесных формул. Угловые скобки в блоке 4 выделяют части текстов, пропущенные в примерах для краткости, круглые скобки - автора письма и адрес текстового фрагмента в книге-источнике.

1. ЖАЛОБА И СОЖАЛЕНИЕ.

2. АХ, БЕДА, БЕЗОБРАЗИЕ, БОЛЬНО, ГОРЕ, ГОРЬКО, ГРУСТНО, ДОСАДА, ДОСАДНО, ДРЯНЬ, ЖАЛЕТЬ, ЖАЛКИЙ, ЖАЛКО, ЖАЛЬ, К НЕСЧАСТЬЮ, К СОЖАЛЕНИЮ, МУЧИТЕЛЬНО, НАКАЗАНИЕ, НЕЛЕГКО, НЕНАВИДЕТЬ, НЕПРИЯТНО, НЕПРИЯТНЫЙ, НЕСЧАСТЬЕ, ОБИДНО, ОГОРЧЕНИЕ, ОГОРЧИТЬ, ОДИНОКИЙ, ОДИНОКО, ПАДАТЬ ДУХОМ, ПЕЧАЛИТЬ, ПЕЧАЛЬ, ПЕЧАЛЬНО, ПЕЧАЛЬНЫЙ, ПЛОХО, ПЛОХОЙ, РАЗОЧАРОВАНИЕ, СКВЕРНЫЙ, СКУЧНО, СОЖАЛЕНИЕ, СОЖАЛЕТЬ, СОСКУЧИТЬСЯ. ТОСКА, ТОСКЛИВО, ТРУДНО, ТЯЖЕЛО, ТЯЖЕСТЬ, УВЫ, УЖАС, УЖАСНО, УЖАСНЫЙ, УСТАТЬ, (НЕ)ХВАТАТЬ, ХОТЕТЬСЯ, ЭХ.

3. Ах, почему я не сделал этого!

Ах, как бы я хотел, чтобы...!

(Ах, как) (мне) больно, горько, грустно, досадно, жалко, жаль, обидно, печально, плохо, скверно, ... (, что) (!) (Так) больно, грустно, ... (, что ...)!

Беда!

(У меня) беда, несчастье.

Безобразие!

(Это) (очень) больно, горько, грустно, досадно, неприятно, обидно, печально, тяжело.

(Вот, какая, вот какая) досада!

(...) к (моей) величайшей досаде, ...

(Я) жалею, что...

$(\ldots$,$) к (великому, глубокому, моему глубоко-$ му) сожалению, ...

Что за наказание!

Я себя ненавижу.

$(\ldots$,$) к несчастью, ...$

Меня (очень) огорчает, огорчило, печалит, опечалило, что ... Это меня огорчает, огорчило. Я (очень) огорчен (тем), что... Меня огорчает, огорчило...

Я в отчаянии.

С печалью я думаю о...

Какое разочарование!

Скучно и грустно.

$(\ldots$,$) к (великому, глубокому, моему глубоко-$ му) сожалению, ...

(Я) (очень, чрезвычайно) сожалею, что...

Увы! Увы мне!

Как мне не хватает... !

$Э \mathrm{x} ! Э \mathrm{x}, \ldots$
4. У меня начинает являться сильное подозрение, что 2000 р. ухнут в море русской революции. Ах, как пригодились бы мне эти две тысячи! Но не буду себя излишне расстраивать и вспоминать о них! (Булг., с. 389). < ...>. Так больно, что я не мог эти дни писать тебе... (Пауст., с. 19). <..>. Очень жалею, что я не могу и не мог к праздникам сделать для них что-нибудь приятное (Чех., с. 158-159). <... . Сегодня, пробегая экземпляр, обнаружил еще один сюрприз, неприятнейшим образом поразивший меня (Булг., с. 541). <..>. Ваше письмо бесконечно обрадовало меня, и я буду очень счастлива возвратиться к прежним отношениям, тем более что более одинокой, чем я, даже и быть нельзя (Ахм., с. 13). $<. .>$. В Москве, к сожалению, нам не удалось обстоятельно побеседовать, посидеть часок у стола (C.-M., c. 338). <...>.

Следует заметить, что вариативность высказываний, отраженных в блоках 3 и 4, гораздо выше, чем в данном примере, но невозможно и нет необходимости приводить все варианты с разнообразными личными местоимениями, глагольными формами, порядком слов и т. д.

Функционально-идеографический словарь по письмам русских писателей отражает движение мысли носителя языка (как выражается тот или иной смысл в текстах писем, какие смыслы выражаются в тех или иных текстовых фрагментах). Один и тот же текстовый фрагмент может содержать несколько СК. По логике использования СК отражают аспекты содержания текстовых фрагментов и с точки зрения классификации являются фасетами. Вероятно, на основе этих фасетов можно будет выделить виды содержания (или жанры, речевые стили) текстовых фрагментов. Подобный функционально-идеографический словарь можно использовать в качестве письмовника, а также в процессе изучения филологических дисциплин - стилистики, культуры речи, риторики, теории и истории литературы.

\section{Выводы}

Таким образом, СК в словарях идеографического типа отражают когнитивные аспекты языка - проблемную ситуацию в словоупотреблении и понимании, классификацию лексических единиц и понятий, психологическую сторону процессов и результатов мыш- 
ления в языковых формах. СК связаны не только с языковыми единицами и их логическими свойствами, но и с экстралингвистическими факторами, которые имеют свою специфику в разных дискурсах. Методика формирования набора СК в различных дискурсах обусловлена прагматическими задачами и характером деятельности, в которой используется язык.

\section{СПИСОК ЛИТЕРАТУРЫ}

Адмони В. Г., 1964. Основы теории грамматики. М. ; Л. : Наука. 105 с.

Бондарко А. В., 1984. Функциональная грамматика. Л. : Наука. 134 с.

Бондарко А. В., 1990. Функционально-семантическое поле // Лингвистический энциклопедический словарь. М. : Сов. энцикл. С. 566-567.

Виноградов С. Н., 1997. Функционально-идеографический принцип описания семантики текста (на материале писем русских писателей) // Освоение семантического пространства русского языка иностранцами : тез. докл. междунар. конф. Нижний Новгород : Нижегород. гос. лингвист. ун-т. С. 7-8.

Виноградов С. Н., 2007. Аксиологический аспект словоупотреблений и текстовых повторов // Вестник Нижегородского университета им. Н.И. Лобачевского. № 7. С. 265-269.

Виноградов С. Н., 2016. Смысловые категории и смысл текста // Успехи современной науки и образования. Т. 3, № 10. С. 7-12.

Виноградов С. Н., Глумов В. И., Ломакина О. А., Максимов В. Р., Русова Н. Ю., 1981. Особенности лингвистического обеспечения отраслевой автоматизированной системы научно-технической информации промышленности строительных материалов // Научно-техническая информация. Серия 2: Информационные процессы и системы. № 2. С. 11-15.

Головин Б. Н., Кобрин Р. Ю., 1987. Лингвистические основы учения о терминах. М. : Высш. шк. 104 с.

Гухман М. М., 1971. Единицы анализа словоизменительной системы и понятие поля // Фонетика. Фонология. Грамматика : сб. ст. М. : Наука. С. $163-170$.

Караулов Ю. Н., 1981. Лингвистическое конструирование и тезаурус литературного языка. М. : Наука. 367 c.

Козлинская О. А., 2009. Изучение смысловой структуры школьного сочинения // Вестник Нижегородского университета им. Н.И. Лобачевского. № 6 (2). С. 255-259.
Козлинская О. А., 2011. Описание функциональносемантического поля «Сопоставление» в тексте школьного сочинения // Вестник Нижегородского университета им. Н.И. Лобачевского. № 1. С. 363-366.

Куликова И. С., Салмина Д. В., 2002. Введение в металингвистику (системный, лексикографический и коммуникативно-прагматический аспекты лингвистической терминологии). СПб. : Сага. 352 c.

Лакофф Дж., 1988. Мышление в зеркале классификаторов // Новое в зарубежной лингвистике. Когнитивные аспекты языка. М. : Прогресс. Вып. XXIII. C. 12-51.

Плунгян В. А., 2003. Общая морфология. Введение в проблематику. М. : УРСС. 342 с.

Плунгян В. А., 2011. Введение в грамматическую семантику: грамматические значения и грамматические системы языков мира. М. : Рос. гос. гуманитар. ун-т. $672 \mathrm{c}$.

Скороходько Э. Ф., 1970. Семантические сети и некоторые количественные характеристики терминологической лексики // Лингвистические проблемы научно-технической терминологии. М. : Наука. С. 160-170.

Соссюр Ф. де, 1977. Труды по языкознанию. М. : Прогресс. 696 c.

Черный А. И., 1975. Введение в теорию информационного поиска. М. : Наука. 238 с.

Чернявская В. Е., 2006. Интерпретация научного текста. М. : КомКнига. 128 с.

Щур Г. С., 1974. Теории поля в лингвистике. М. : Наука. 256 c.

\section{ИСТОЧНИКИ И СЛОВАРИ}

Большой толковый психологический словарь Большой толковый психологический словарь. В 2 т. Т. 1. А - О : пер. с англ. М. : Вече : АСТ, $2000.592 \mathrm{c}$.

ИПТ, 1980 - Информационно-поисковый тезаурус по промышленности строительных материалов. Раздел «Стекло и стеклоизделия». Первая редакция. М. : ВНИИЭСМ, $1980.185 \mathrm{c}$.

ИПТ, 1981 - Информационно-поисковый тезаурус промышленности строительных материалов ОАСНТИ-СМ. Раздел «Цементная промышленность». Первая редакция. М. : ВНИИЭСМ, $1981.215 \mathrm{c}$.

Новая философская энииклопедия - Новая философская энциклопедия. В 4 т. Т. 2 / Ин-т философии РАН. М. : Мысль, 2001. 634 с.

Ожегов, Шведова - Ожегов С. И., Шведова Н. Ю. Большой толковый словарь русского языка. В 5 т. Т. 2. М. : Азъ, 1992. 506 c. 
Современный философский словарь - Современный философский словарь / под общ. ред. д-ра филол. наук, проф. В. Е. Кемерова. 3-е изд., испр. и доп. М. : Академический проект, 2004. 864 с.

ТИП - Тезаурус информационно-поисковый по промышленности строительных материалов АСНТИ-СМ. Раздел «Керамическая промышленность». Первая редакция. М. : ВНИИЭСМ, $1983.266 \mathrm{c}$.

Философский словарь - Философский словарь / под ред. И. Т. Фролова. 7-е изд, перераб. и доп. М. : Республика, 2001. 719 c.

Философский эничиклопедический словарь - Философский энциклопедический словарь. М. : ИНФРА-М, 1999. 576 с.

\section{REFERENCES}

Admoni V.G., 1964. Bases of the Theory of Grammar. Moscow; Leningrad, Nauka Publ. 105 p.

Bondarko A.V., 1984. Functional Grammar. Leningrad, Nauka Publ. 134 p.

Bondarko A.V., 1990. Functional-Semantic Field. Lingvisticheskiy entsiklopedicheskiy slovar [Linguistic Encyclopedic Dictionary]. Moscow, Sovetskaya entsiklopediya Publ., pp. 566-567.

Vinogradov S.N., 1997. Functional and Ideographic Principle of the Text Semantics Description (on the Basis of Letters of Russian Writers). Osvoenie semanticheskogo prostranstva russkogo yazyka inostrantsami: tezisy dokladov mezhdunarodnoy konferentsii [Learning Semantic Space of the Russian Language by Foreigners: Abstracts of Reports of the International Conference]. Nizhny Novgorod, Nizhegorodskiy gosudarstvenniy lingvisticheskiy universitet Publ., pp. 7-8.

Vinogradov S.N., 2007. The Axiological Aspect of Word Usage and Text Repetitions. Vestnik Nizhegorodskogo universiteta im. N.I. Lobachevskogo [Vestnik of Lobachevsky University of Nizhni Novgorod], no. 7, pp. 265-269.

Vinogradov S.N., 2016. Sense Categories and Sense of the Text. Uspekhi sovremennoy nauki $i$ obrazovaniya [Success of Modern Science and Education], vol. 3, no. 10, pp. 7-12.

Vinogradov S.N., Glumov V.I., Lomakina O.A., Maksimov V.R., Rusova N.Yu., 1981. Features of the Lingware of the Branch Automated System of Scientific and Technical Information of the Industry of Construction Materials. Nauchnotekhnicheskaya informatsiya. Seriya 2. Informatsionnye protsessy $i$ sistemy [Scientific and Technical Information. Series 2: Information Processes and Systems], no. 2, pp. 11-15.
Golovin B.N., Kobrin R.Yu., 1987. Linguistic Foundations of the Doctrine of Terms. Moscow, Vysshaya shkola Publ. 104 p.

Gukhman M.M., 1971. Units of the Inflectional System Analysis and the Concept of Language Field. Fonetika. Fonologiya. Grammatika: sbornik statey [Phonetics. Philology. Grammar: Collection of Articles]. Moscow, Nauka Publ., pp. 163-170.

Karaulov Yu.N., 1981. Linguistic Designing and the Thesaurus of a Literary Language. Moscow, Nauka Publ. 367 p.

Kozlinskaya O.A., 2009. A Study on the Semantic Structure of a School Essay. Vestnik Nizhegorodskogo universiteta im. N.I. Lobachevskogo [Vestnik of Lobachevsky University of Nizhni Novgorod], no. 6 (2),pp. 255-259.

Kozlinskaya O.A., 2011. Description of the "Comparison" Functional and Semantic Field in the Text of a School Essay. Vestnik Nizhegorodskogo universiteta im. N.I. Lobachevskogo [Vestnik of Lobachevsky University of Nizhni Novgorod], no. 1, pp. 363-366.

Kulikova I.S., Salmina D.V., 2002. Introduction to Metalinguistics (System, Lexicographic and Communicative and Pragmatical Aspects of Linguistic Terminology). Saint-Petersburg, Saga Publ. 352 p.

LakoffDzh., 1988. Thinking in the Mirror of Classifiers. Novoe varubezhnoy lingvistike. Vypusk XXIII. Kognitivnye aspekty yazyka [New Trends in Foreign Linguistics. Issue XXIII. Cognitive Aspects of Language]. Moscow, Progress Publ., pp. 12-51.

Plungyan V.A., 2003. General Morphology. Introduction to Problematics. Moscow, URSS Publ. 342 p.

Plungyan V.A., 2011. Introduction to Grammatical Semantics: Grammatical Meanings and Grammatical Systems of the Languages of the World. Moscow, Rossiyskiy gosudarstvenniy gumanitarniy universitet Publ. 672 p.

Skorokhodko E.F., 1970. Semantic Networks and some Quantitative Characteristics of Terminological Vocabulary. Lingvisticheskie problemy nauchnotekhnicheskoy terminologii [Linguistic Problems of Scientific and Technical Terminology]. Moscow, Nauka Publ., pp. 160-170.

Sossyur F. de, 1977. Works on Linguistics. Moscow, Progress Publ. 696 p.

Chernyy A.I., 1975. Introduction to the Theory of Information Search. Moscow, Nauka Publ. 238 p.

Chernyavskaya V.E., 2006. Interpretation of Scientific Text. Moscow, KomKniga Publ. 128 p.

Shchur G.S., 1974. Theories of a Field in Linguistics. Moscow, Nauka Publ. 256 p. 


\section{SOURCES AND DICTIONARIES}

Large Explanatory Psychological Dictionary. In 2 vols. Vol.1. A-O. Moscow, Veche; AST Publ., 2000.592 p.

Information Retrieval Thesaurus on Building Material Industry. Glass and Glass Products Section. First Edition. Moscow, VNIIJeSM Publ., 1980.185 p.

Information Retrieval Thesaurus on Building Material Industry of the Branch Automated System of Scientific and Technical Information, Building Materials. Cement industry Section. First Edition. Moscow, VNIIJeSM Publ., 1981.215 p.

New Philosophical Encyclopedia. In 4 vols. Vol. 2. E-M. Moscow, Mysl Publ., 2001. 634 p.
Ozhegov S.I., Shvedova N.Yu. Large Dictionary of the Russian Language. In 5 vols. Vol. 2. Moscow, Az Publ., 1992. 506 p.

Kemerov V.E., ed. Modern Philosophical Dictionary. Moscow, Akademicheskiy proekt Publ., 2004. $864 \mathrm{p}$.

Information Retrieval Thesaurus on the Construction Material Industry of the Branch Automated System of Scientific and Technical Information, Building Materials. Ceramic industry Section. First edition. Moscow, VNIIJeSM Publ., 1983. $266 \mathrm{p}$.

Frolov I.T., ed. Philosophical Dictionary. Moscow, Respublika Publ., 2001. 719 p.

Philosophical Encyclopedic Dictionary. Moscow, INFRA-M Publ., 1999. 576 p.

\section{Information about the Author}

Sergey N. Vinogradov, Doctor of Sciences (Philology), Professor, Department of Modern Russian Language and General Linguistics, Lobachevsky State University of Nizhny Novgorod, Bolshaya Pokrovskaya St., 37, 603000 Nizhny Novgorod, Russia, vinogradov54@mail.ru, http://orcid.org/00000001-5321-4932

\section{Информация об авторе}

Сергей Николаевич Виноградов, доктор филологических наук, профессор кафедры современного русского языка и общего языкознания, Нижегородский государственный университет им. Н.И. Лобачевского, ул. Большая Покровская, 37, 603000 г. Нижний Новгород, Россия, vinogradov54@mail.ru, http://orcid.org/0000-0001-5321-4932 